\title{
Recent advances in the treatment of pain
}

\section{Mellar P Davis ${ }^{1,2}$}

Addresses: ${ }^{1}$ Taussig Cancer Institute - Cleveland Clinic, Cleveland, OH, USA; ${ }^{2}$ Cleveland Clinic Lerner School of Medicine, Case Western Reserve University, Cleveland, OH 44195, USA

Email: davism6@ccf.org

Fl000 Medicine Reports 2010, 2:63 (doi:10.3410/M2-63)

The electronic version of this article is the complete one and can be found at: http://fl000.com/reports/medicine/content/2/63

\begin{abstract}
Cancer pain and chronic non-malignant pain can be difficult to manage and may not respond satisfactorily to standard analgesics. Sequential empiric analgesic trials are usually done to manage individual patients. Experimental human pain models have helped to clarify mechanisms of opioid and adjuvant analgesic actions. Combinations of opioids and adjuvant analgesics better relieve pain than either opioids or adjuvant analgesics alone, as demonstrated in randomized controlled trials. The analgesic activity of antidepressants is largely dependent upon norepinephrine reuptake and activation of alpha 2 adrenergic receptors. Corticosteroids reduce postoperative orthopedic incident pain, which may allow patients to ambulate earlier and with less pain. Spinal corticosteroids reduce lower hemibody pain. Gabapentinoids as single high doses reduce postoperative pain and certain acute pain syndromes. Individuals who experience flares of pain while on spinal opioids benefit from intrathecal boluses of levobupivicaine or sublingual ketamine. Interventional approaches to pain management are often necessary due to the limitations of systemic analgesics. Electronics stimulators (peripheral, spinal and motor cortex) improve difficult to manage chronic pain syndromes. Pulsed radiofrequency reduces pain without tissue damage, which could be an advantage over chemical or radiofrequency neurotomy. Botulinum toxin A reduces focal neuropathic pain that is durable. Interventional related successes in relieving pain are operator dependent. Most reported benefits of systemic and regional analgesics and interventional approaches to pain relief are not based on randomized trials and are subject to selection bias, sampling error, and placebo responses, which may over-inflate reported benefits. Randomized controlled trials are needed to confirm reported benefits.
\end{abstract}

\section{Introduction and context}

The management of pain is a complex problem. Cancerrelated pain, post-operative pain, and painful flares of chronic pain are difficult to treat. However, pain management is a fundamental human right and so clinicians need to be knowledgeable about analgesics and interventional approaches to pain management [1]. Single-agent analgesics are frequently ineffective and analgesic rotation or combinations are prescribed with little evidence of additive or synergistic benefits [2]; multiple adjuvant analgesics are frequently used with opioids without strong evidence as to effectiveness [3-6]. Evidence for benefits in neuropathic pain is often based on disease-oriented trials but recent research is starting to focus on pathophysiologic mechanisms of action of analgesics $[7,8]$.

The clinical benefits of analgesics are difficult to evaluate. Confounders such as baseline pain variability, emotional state and associated disease-related symptoms bias outcomes [9]. Placebo responses are substantial, overinflating analgesic response in single arm studies and diminishing anticipated benefits in randomized studies. Frequently, individuals with chronic pain have several pains, one of which responds better to an analgesic than the other(s). 


\section{Recent advances}

\section{Analgesic management of pain}

Experimental pain models involve acute skin, nasal, and dental mucosa pain, muscle pain, diffuse noxious inhibitory control (DNIC), and hyperalgesia/central sensitization. Pain intensity, location, frequency, and duration are controlled in these models to limit confounders and better explore analgesic responses to pain mechanisms. These models are valuable tools for characterizing analgesic actions beyond pharmacodynamic information derived from receptor or channel interactions [10]. Using these models, Staahl and colleagues [11] recently reported a systematic review of non-opioid analgesic responses in human experimental pain. Aspirin improved acute pain, was ineffective in ischemic muscle pain but, interestingly, improved hyperalgesia and central sensitization. Ibuprofen had the same spectrum of activity, including reduction of mechanical hyperalgesia. In contrast, $N$-methyl $D$-aspartate (NMDA) receptor antagonists did not reduce acute pain but did reduce muscle pain and secondary hyperalgesia. Gabapentin was not effective in acute pain but blocked hyperalgesia. Gabapentin did not enhance DNIC whereas lamotrigine did but did not relieve cutaneous hyperalgesia. Tricyclic antidepressants reduced acute pain and visceral pain but did not enhance DNIC.

Delta-9 tetrahydrocannabinol was found to be not effective in acute pain or hyperalgesia. Smoked cannabis, which contains several cannabis analogues, reduced spontaneous pain from intradermal capsaicin. A recent study reported that the combination of tetrahydrocannabinol (THC) and cannabidiol was more effective in relieving cancer pain than THC alone [12]. Hence, cannabis combinations and $\mathrm{CB}_{2}$ receptor agonists should be explored further in clinical trials. Combinations may improve pain and/or diminish side effects, thus extending the THC therapeutic index.

Several recent studies have demonstrated benefits from combinations of opioids and adjuvant analgesics, which produce superior pain control compared to single analgesics even though the maximum tolerable doses of both drugs are less in combination. Effective combinations include oxycodone plus pregabalin [13], morphine plus gabapentin [14] and nortriptyline plus gabapentin [15]. The mechanisms behind the added benefits are not known but presumably are due to complementary receptor interactions that diminish pain or reduce opioid analgesic tolerance. It is speculated that gabapentin and pregabalin block calcium channels that are upregulated by opioids [16]. Gabapentin requires activated $5 \mathrm{HT}_{3}$ (serotonin) receptors for analgesia $[17,18]$.
The choice of antidepressants for chronic pain is clinically important [19]. Tricyclic antidepressants have greater evidence for benefit in acquired pain processing disorders (neuropathic pain, headaches, low back pain, fibromyalgia, and irritable bowel syndrome) while newly developed selective serotonin and norepinephrine reuptake inhibitors have less supportive evidence. Selective serotonin reuptake inhibitors are generally ineffective. Overall adrenergic (alpha-2-adrenergic) receptor activation is more important to antidepressant analgesic activity than activation of serotonin receptors.

There is good evidence that alpha-2-adrenoceptors mediate inhibitory descending brain stem control over dorsal horn nociceptive traffic and that the serotonin $5 \mathrm{HT}_{3}$ receptor facilitates dorsal horn nociceptive processing [20]. Pain processing disorders such as fibromyalgia and irritable bowel syndrome are putatively the result of endogenous central monoamine imbalances, which cause the brainstem nociceptive modulator to malfunction. This may be the reason why antidepressants that selectively reduce serotonin reuptake are less effective adjuvant analgesics and be why norepinephrine is the important monoamine when dampening pain processing [18].

Dexamethasone reduces pain in several clinical scenarios. Preoperative dexamethasone $(40 \mathrm{mg})$ selectively reduces dynamic (incident) pain after total hip replacement [21]. The benefits were quite dramatic. Incident pain in this study was reduced to 2.7 (95\% confidence interval 2.2-3.1) in the numerical rating scale (NRS) score $(0=$ no pain, $10=$ severe pain $)$ compared to no response (NRS 6.8) with placebo (95\% confidence interval 6.4-7.2; $P<0.0001$ ). Rest pain and cumulative morphine doses, however, were not reduced. Postoperative nausea was also less with dexamethasone, which is an additional benefit. Ambulation after hip replacement is limited by incident pain; dexamethasone appears to facilitate early mobilization and may reduce hospital stay. Both outcomes need to be included in a confirmatory trial before this becomes routine practice.

A second study involved 10 individuals with intractable lower hemibody cancer pain. Weekly intrathecal betamethasone $(2 \mathrm{mg}$ ) produced analgesia quickly (within 30 minutes). Half of the individuals had pain relief lasting 7 days [22]. Repeat intrathecal injections at 7-day intervals may be clinically problematic unless an intrathecal catheter is in place. Analgesic tolerance to intrathecal dexamethasone was not determined in this study. Persistent responses with repeated injections would be an important outcome. However, in those with a short time to live ( 1 to 2 weeks), this may be a reasonable option in lieu of spinal analgesia. 
Several studies have found that preoperative dexamethasone improves acute postoperative pain $[23,24]$. However, this is not observed in all studies [25]. The mechanism by which dexamethasone improves postoperative analgesia is not well understood. Morphine increases central nervous system glutamate levels and dexamethasone increases glutamate transporter expression, which increases glutamate clearance from synaptic clefts [26-28]. Hence, dexamethasone appears to acutely reduce morphine analgesic tolerance or blunt counteropioid responses. It would be of interest to know if cerebrospinal fluid glutamate levels are reduced by dexamethasone in morphine-tolerant individuals.

Gabapentinoids reduce postoperative pain after craniotomy [29]. The opioid sparing effects of preoperative gabapentin (doses range between 300 and $1200 \mathrm{mg}$ ) are from 20 to $60 \%$ [30,31]. Gabapentin, besides blocking voltage-gated calcium channels, also blocks thrombospondin binding to alpha-2-delta-1 calcium channel subunits, which are responsible for synaptogenesis and excitatory synapse formation [32]. Preventing excitatory synapse formation and pain-induced neuroplasticity will reduce long-term postoperative pain syndromes (postmastectomy pain and post-thoracotomy pain). The effective dose and duration of gabapentin treatment to achieve these benefits are not known but should be explored. Gabapentin also reduces acute zoster pain and allodynia with a single dose of $900 \mathrm{mg}$ [33]. At least in certain clinical settings gabapentin produces a rapid response.

Rarely do spinal opioids completely relieve pain but this may be due to patient selection. In general, individuals considered for spinal analgesia are highly opioidtolerant, and as a result systemic opioid doses for transient flares of pain are less likely to be effective or are required in high doses, leading to toxicity. Mercadante and colleagues [34] reported the use of either spinal bolus levobupivicaine or sublingual ketamine for breakthrough pain episodes. Individuals in the study were treated by spinal analgesia (local anesthetics, clonidine, and morphine) and experienced unacceptable side effects and/or little pain relief from systemic morphine (mean dose $36 \mathrm{mg}$ ) for pain flares. Spinal bolus levobupivicaine (mean dose $1.5 \mathrm{mg} / 0.6 \mathrm{ml}$ ) through a side port or sublingual ketamine $(25 \mathrm{mg}$ ) reduced pain severity by $50 \%$ within 5 minutes of administration. Leg weakness was seen in $10 \%$ of episodes treated with spinal levobupivicaine. One individual experienced a pleasant sensation of dreaming with ketamine. One cannot exclude a placebo response since this was a case series and not a randomized blinded controlled trial. There is very little published experience on how to manage pain flares on spinal opioids, but for the present time, until better evidence becomes available, Mercadante and colleagues have given us an approach to managing this rare but difficult clinical scenario.

\section{Interventional approaches to pain management}

\section{Electronic stimulators}

Transcutaneous nerve, spinal cord, and motor cortex stimulators have been used to reduce chronic pain that is poorly responsive to systemic analgesics. Short-term high frequency and low frequency transcutaneous nerve stimulators were used by 24 individuals who suffered from chronic pain secondary to spinal cord injury [35]. Patients used short bursts of high frequency $(80 \mathrm{~Hz})$ or low frequency $(2 \mathrm{~Hz})$ stimulation three times daily for 2 weeks. Crossover was performed after a 2-week period. Pain relief (measured using a five point global relief scale) was reported in $29 \%$ of patients on high frequency and $38 \%$ on low frequency stimulation. No improvement was observed in mood, coping, life satisfaction, sleep quality, and psychosocial pain. Of the 24 patients, 6 elected to continue with transcutaneous nerve stimulation. Comparison to usual care would have been helpful when assessing benefits of transcutaneous nerve stimulation in this population. One cannot exclude a placebo response.

There is little published experience of the long-term benefits of peripheral nerve stimulators, but a study on long-term benefits was reported by Van Calenbergh and colleagues [36]. Of 11 individuals treated since the 1980s, 5 were re-examined for pain and studied using quantitative sensory testing. Pain intensity was still reduced by stimulators and unpleasantness improved (as measured by the visual analogue scale [VAS] and verbal rating scale). The stimulator had a continued benefit to sleep and physical function. Quantitative sensory testing found no change in cold or heat thresholds whether the stimulator was on or off. This study demonstrates long-term benefits in a subset of patients on transcutaneous nerve stimulators; in addition, tachyphylaxis to pain responses (analgesic tolerance) may not occur.

Spinal cord stimulators have been used for complex regional pain syndromes, diabetic neuropathy, postherpetic neuralgia, pain from peripheral vascular disease, and low back pain. A small series of patients who had cervical neck pain after back surgery underwent cervical epidural stimulator placement by percutaneous thoracic needle directed implantation [37]. This was successfully performed in four of five eligible individuals. Pain over the neck and upper extremities was reduced by $70-90 \%$ in this small group of individuals and pain responses 
were durable up to 9 months. These patients are not usual candidates for regional analgesia and were likely to have been opioid-tolerant. This procedure may be considered in those individuals whose pain does not respond to systemic analgesics and in whom spinal analgesia is not possible.

Spinal cord stimulators will improve complex regional pain syndromes if the segment of body area involved with pain is small. Spinal cord stimulators cannot adequately treat large body segments affected by regional pain. Velasco and colleagues [38] reported the use of motor cortex stimulators in managing complex regional pain syndrome. Five individuals underwent a small craniotomy and unilateral 20 grid contact implantation on the motor cortex, guided by craniometric landmarks. Pain and sympathetic symptoms (perspiration, regional temperature, skin color, and swelling) were evaluated over 1 year using standard instruments. Four of five individuals had improvement in pain, sensory, and sympathetic symptoms. VAS and McGill Pain Questionnaire scores improved significantly. This procedure requires neurosurgical expertise and should be limited to high volume, experienced institutions. The benefits to this small group of individuals appear to be substantial and durable.

A second study reported the use of motor cortex stimulation to treat peripheral neuropathy refractory to usual management [39]. Sixteen individuals with a variety of peripheral neuropathies (trigeminal neuralgia, brachial plexopathy, ambulation-related pain, neurofibromatosis, herpetic ophthalmicus, atypical facial pain, and traumatic nerve trunk injury) underwent implantation of quadrupolar leads under radiological guidance. The epidural cortical stimulator location was secondarily confirmed by electrophysiologic studies. The stimulator was switched on and off at monthly intervals and patients were assessed by the Brief Pain Inventory, VAS for pain severity, and McGill Pain Questionnaire. Thirteen individuals underwent 'on' and 'off' stimulation assessment. The scores on the McGill Pain Questionnaire pain rating index and sensory subscore improved with stimulation. The effects appeared to linger during the 'off' stimulation month. The median VAS pain score decreased by $48 \%$ (individual range $0-95 \%$ ).

Anodal transcranial direct current stimulation is one way of non-invasively stimulating the motor cortex. Antal and colleagues [40] used this method to treat chronic pain syndromes, including trigeminal neuralgia, poststroke pain, back pain, and fibromyalgia. Twelve patients underwent both anodal and sham stimulation and nine underwent either anodal or sham stimulation. Current was applied to the 'hand' area of the $M_{1}$ cortex for 20 minutes using $1 \mathrm{~mA}$ current for 5 consecutive days. The crossover was randomized, double blinded, and occurred at 6 weeks only if the VAS for pain severity returned to baseline 10 days prior to the next anodal stimulation (or sham stimulation). This was done to avoid a carryover analgesic effect. VAS was rated daily for 1 month before, during, and after stimulation. Anodal direct current stimulation was superior to sham stimulation and lasted 3-4 weeks after stimulation was finished. No patient experienced severe adverse effects. The mechanism of action postulated by the investigators is a decrease in intracortical inhibition and increased cortico-cortical excitability. Activation of the motor cortex produces long-lasting inhibition of the subthalamic nucleus [41-43]. The subthalamic nuclei project to ventral thalamus. The dorsal subnucleus reticularis dorsalis contains neurons involved in the convergence of widespread nociceptive signals $[44,45]$. Hence, longterm inhibition of the subthalamic nuclei may be the mechanism of analgesia in this case by dampening thalamic nociceptive traffic and blocking nociceptive convergence.

\section{Pulsed radiofrequency}

Pulsed radiofrequency involves short bursts of radiofrequency energy applied to nervous tissue. Unlike continuous radiofrequency ablation, it produces little tissue destruction but lasting inhibition of evoked synaptic activity [46]. Pulsed radiofrequency induces cellular distress as measured by expression of neuron activation transcription factor-3 (ATF-3), and both C and A delta sensory fibers appear to be selectively targeted by it [47]. Ultrastructural changes include abnormal membranes and mitochondria morphology and disrupted and disorganized microfilaments and microtubules [48]. Ultrastructural changes are greater in $\mathrm{C}$ fibers than A beta fibers.

Splanchnic pulsed radiofrequency has been used to treat chronic benign pancreatic pain [49]. Pancreatic pain is poorly responsive to pancreatic enzyme supplements, systemic analgesics, anti-oxidants, surgical drainage, and celiac block. Percutaneous splanchnic block may be more successful than celiac block due to a more predictable anatomy. Blocks using alcohol or phenol can cause cardiac arrhythmia or paralyze the diaphragm. Continuous radiofrequency ablation of the splanchnic nerve produces good analgesic responses in $40 \%$ of individuals. The authors reported excellent responses in individuals using pulsed radiofrequency splanchnic blocks. The relative lack of tissue destruction and the avoidance of alcohol potentially make this procedure safer than standard approaches. However, randomized 
trials comparing this technique to conventional interventional approaches will need to be done to confirm these results.

Occipital neuralgia produces paroxysmal non-throbbing, stabbing pain in the area of the greater and lesser occipital nerve, with most episodes (85\%) being unilateral. Vanelderen and colleagues [50] used pulsed radiofrequency as a means of reducing the pain intensity from occipital neuralgia. Patients were chosen for this singlearm study based on response to bupivicaine injections into the offending nerve, defined as a $50 \%$ reduction in the VAS score for pain intensity. A 23 gauge CXE-6 needle (Cotop International BV, Amsterdam, The Netherlands) was used with a lesion generator (Cosman RFG-1B generator, Cosman Medical Inc., Burlington, MA; $50 \mathrm{~Hz}$, $0.5 \mathrm{~V}$ ). The primary outcome was pain, quantified by VAS and Likert scale. Secondary outcomes were quality of life and reduction in analgesic use. Of 19 patients who underwent pulsed radio-frequency, 13 had a $50 \%$ or greater improvement in pain severity. The VAS score was $7.5 \mathrm{~cm}$ at baseline, $3.5 \mathrm{~cm}$ at 2 months, and $3.8 \mathrm{~cm}$ at 6 months. Daily activities improved as well as mood and sleep disturbances. No adverse effects were noted. This approach should be compared to local injections of botulinum toxin A (Botox), subcutaneous neurostimulation, and $\mathrm{C}_{1}-\mathrm{C}_{4}$ block or rhizotomy. As this was a select group of patients, responses may have been inflated by selection bias. However, this is a one-time procedure that does not cause tissue damage and has durable benefits, all of which are encouraging. The response to repeat pulsed radiofrequency with relapse would be of interest.

Lateral branch radiofrequency ablation significantly reduces sacroiliac pain in $50 \%$ of individuals. Significant in this setting is defined as a $50 \%$ reduction in pain severity lasting at least 6 months [51]. However, when using pulsed radiofrequency the location of the electrode may be critical to analgesic benefits, much more so than with continuous radiofrequency neurotomy. In a randomized trial involving individuals with chronic postsurgical thoracic pain, pulsed radiofrequency of the dorsal root ganglion reduced pain in over $60 \%$ of individuals whereas pulsed radiofrequency of the intercostal nerve and standard medical management reduced pain in $21 \%$ and $27 \%$, respectively (at 6 weeks). The durability of response for those undergoing pulsed radiofrequency of the dorsal root ganglion was greater when assessed at 3 months compared to those undergoing intercostal nerve pulsed radiofrequency or receiving systemic analgesic [52]. Hence, the benefits in response and duration depend on where pulse radiofrequency is performed in relation to the nerve. The optimal site appears to be at the dorsal root ganglion.

\section{Continuous radiofrequency neurotomy}

Neuropathic (post-mastectomy) pain after breast cancer surgery can be debilitating. Corticosteroids have been used with nerve blocks and radiofrequency neurotomy to treat neuropathic pain. A small series of three patients with post-mastectomy pain were treated with paravertebral nerve radiofrequency neurotomy combined with corticosteroids [53]. Treatment was repeated at 2-month intervals as needed and a total of 21 procedures were done on these three patients. All three experienced pain relief and improved quality of life, but regional hypoesthesia worsened slightly with treatment. The average number of procedures per patient was seven, which means either the response duration was short or multiple thoracic nerves required radiofrequency neurotomy for response. The addition of corticosteroids may or may not be beneficial and cannot be determined from this study.

Lumbar medial branch neurotomy has been used to treat chronic low back pain. Outcomes are adversely affected by poor patient selection and inaccurate surgical techniques [54]. A randomized trial compared lumbar facet-joint radiofrequency neurotomy with sham neurotomy [55]. Eligible individuals had back pain for more than 6 months and a VAS pain severity $\geq 5$. Of 462 individuals, 81 were eligible and randomly assigned to a treatment group. The first evaluation was 3 months postprocedure and the primary outcome was reduction in pain severity by VAS. Secondary outcomes were physical activity, analgesic consumption and quality of life as measured by the Short Form 36 (SF-36). There was no difference in response between radiofrequency neurotomy $(27 \%)$ and sham (29\%), but global perceived effects favored radiofrequency neurotomy [56]. The authors performed two-level diagnostic intra-articular facet joint blocks before entering patients in the study; blocks and radiofrequency neurotomy were performed at the offending facet(s).

A second randomized trial compared radiofrequency neurotomy of the facet joint versus a sham procedure in 40 patients [57]. This study was double blinded and eligible individuals had three separate positive facet blocks with local anesthetics; a single operator did all the blocks. Primary outcomes were reduction in pain severity by VAS, relief of generalized pain, and global impression of improvement. There was a 1.5 (out of an 11-point pain scale) difference between radiofrequency neurotomy and sham in favor of radiofrequency therapy. Back pain and referred pain were statistically significantly reduced to the same degree as generalized pain. Secondary outcomes were improved with radiofrequency neurotomy. The differences between the two studies may be related to 
design. The requirement of responses to three separate blocks prior to entrance in the study and a single individual performing radiofrequency neurotomy may have been the reasons for the responses.

A systematic review of lumbar facet joint interventions for back pain found that the diagnostic accuracy of local anesthetic blocks is strongly supported by evidence (level I or II-1) while the evidence for radiofrequency neurotomy is level II-2 and II-3 (moderate) due to lower quality of evidence [58].

Radiofrequency facet joint neurotomy should be considered for those who fail to respond to direct application of long-acting corticosteroids. Besides diagnostic techniques, the experience of the operator and imaging modality will be critical to success of radiofrequency neurotomy [59]. The psychological make-up of the individual will predict responses also. Psychologically vulnerable individuals (reduced life control, disturbed mood, negative self-efficacy, catastrophizing, high anxiety, inadequacy, and poor mental health) do not respond as well to treatment [60].

Similar to lumbar facet joint radiofrequency neurotomy, sacroiliac joint radiofrequency neurotomy has limited evidence (level II-3) for benefit in reducing pain [61]. The types of diagnostic tests, criteria for response, patient groups, and block methodology, including imaging, are also likely to be factors predicting responses [62].

Radiofrequency splanchnic neurotomy has been used to reduce pain and analgesic consumption in those suffering from chronic pancreatitis [63]. Endoscopicguided percutaneous radiofrequency cordotomy reduced refractory pain [64]. Radiofrequency neurotomy followed by cementoplasty has been used to treat painful malignant bone lesions in a small number of individuals [65]; post-procedure pain severity in this study was 4.2 , which was significantly less than preprocedure levels (7.9 by VAS). Comparisons should be made between cementoplasty or kyphoplasty alone versus cementoplasty or kyphoplasty plus radiofrequency ablation in future studies.

\section{Botutinum toxin type $A$ (Botox)}

Fewer than $60 \%$ of individuals receive or experience partial relief from neuropathic pain using approved medications. In fact, the number needed to treat to obtain a response in one individual ranges between two and six. Botox has been used for painful disorders associated with muscular contraction (e.g., cervical dystonia and facial spasticity) and glandular secretion (hyperhidrosis) [66]. Acute and chronic pain syndromes are frequently associated with muscle spasm, and preclinical evidence using the rat formalin pain model supports the antinociceptive potential of Botox. Botox injected into the same site as formalin (subplantar surface) inhibited formalin-induced glutamate release from sensory neurons and reduced the expression of Fos-like immunoreactive cells in the dorsal horn [67]. Botox reduced the release of substance $\mathrm{P}$, calcitonin gene-related protein, and vanilloid receptors (such as $\mathrm{TRPV}_{1}$ ). In a case report, Botox injections into the trigger zone of individuals with trigeminal neuralgia reduce pain [68].

Botox has been used to reduce pain and improve gait in patients with unilateral plantar fasciitis. Huang and colleagues [69] performed a randomized double-blind controlled study in 50 individuals with unilateral fasciitis. Those randomized to Botox received 50 units in normal saline injected into the plantar fascia under ultrasound guidance. The control group received normal saline alone. Outcomes were pain severity by VAS, plantar fascia thickness, fat pad thickness, and gait (pressure velocity during first step loading response). Those receiving Botox had a significant reduction in pain at 3 weeks and 3 months compared to controls. Fat pad thickness was unchanged, indicating no inflammatory responses or tissue atrophy.

Forty-five individuals with myofascial pain and headaches were enrolled in a randomized trial in which they were randomly assigned to dry needle, $0.25 \%$ lidocaine, or Botox injections at the trigger points [70]. Outcomes were pain intensity, frequency, duration, local post-injection sensitivity, obtainment time, duration of relief, and use of rescue analgesics and responses were assessed at 12 weeks. All groups responded, with Botox associated with reduced analgesic use and improved local injection sensitivity. The authors recommended that Botox be reserved for those who do not respond to lidocaine trigger point injections only, because of the increased cost.

Ureteral stent placement is associated with pain and urinary frequency and urgency. These symptoms may be related to muscle spasm. Gupta and colleagues [71] performed a randomized, single blinded trial in 51 individuals undergoing ureteral stenting. Botox $10 \mathrm{U} / \mathrm{ml}$ was injected in three locations around the ureteral orifice during stent placement in 30 individuals. Pain and urinary symptoms were assessed using the Urethral Stent Symptom Questionnaire completed 7 days after stent placement. Botox reduced post-stent placement pain (VAS 3.4 versus 6) and opioid use. Botox did not relieve lower urinary tract symptoms. 
Botox injections have been compared to topical isosorbide dinitrate in the management of pain associated with anal fissures [72]. Seventy-three individuals were randomly assigned, of which 37 received Botox. Pain was non-significantly better with isosorbide dinitrate. Healing at 4 months occurred in 14 of 37 individuals who received Botox and 21 of 36 who were treated with isosorbide dinitrate. Isosorbide dinitrate has advantages since it is less expensive, but requires daily continuous application. There appears to be little role for Botox as initial therapy and should be reserved for individuals who do not respond to nitric oxide donor therapy. Combination therapy should be tested in those with anal fissures that fail to respond to single agent therapy.

Ranoux and colleagues [73] performed a randomized double-blinded controlled trial of Botox versus placebo in 29 individuals with focal neuropathies, allodynia, and cold intolerance. Patients received a one-time intradermal injection of Botox (20-190 units) into the painful area. Outcomes were average spontaneous pain severity, quantitative thermal and mechanical perception, allodynia to brushing, neuropathic symptoms, global impression of benefit, and quality of life; these outcomes were measured at baseline, 4, 12, and 24 weeks. Botox reduced spontaneous pain relative to placebo from weeks 2 to 14 . Thermal sensation was preserved with Botox injections. Botox also reduced allodynia and cold sensitivity without altering perception thresholds. The number needed to treat for benefit was three at 12 weeks. Side effects were transient pain at the site of injection. A single injection of Botox at the site of neuropathic pain produces durable responses and may be less expensive than daily lidocaine transdermal patches. This small but well conducted randomized trial provides evidence that Botox is effective in neuropathic pain. Whether this should be used after lidocaine transdermal patches or as a substitution in the management of focal neuropathic pain needs to be addressed in a randomized trial.

\section{Implications for clinical practice}

Adjuvant analgesics influence the cerebral and spinal signatures of pain perception differently [74]. Combining adjuvants and analgesics reduces acute pain, enhances DNIC and reduces central sensitization. Non-steroid antiinflammatory drugs (NSAIDS) may be effective analgesics for neuropathic pain as demonstrated in human experimental pain, animal models, and case reports [75-81]. Antidepressants that block norepinephrine uptake are likely to be more effective adjuvant analgesics than those that inhibit serotonin reuptake. Single dose dexamethasone and gabapentin improve postoperative pain. Dexamethasone may be particularly effective for incident pain after joint replacement. Intrathecal betamethasone reduces lower hemibody pain from cancer. Combinations of tricyclic antidepressants and gabapentin and gabapentinoids plus opioids improve analgesia at lower doses than single analgesics and to a better extent. These findings will influence dosing strategies. It is better to add a second drug to moderate doses of an opioid, gabapentin, or tricyclic antidepressants rather than titrate to high and perhaps toxic doses. Flares of pain with spinal analgesia unresponsive to intravenous morphine may better respond to sublingual ketamine or spinal levobupivacaine.

Non-destructive minimally invasive techniques have been developed to treat refractory pain. These include electronic stimulations, pulsed radiofrequency, and Botox. These therapies have been creatively applied in a small number of individuals. Randomized trials are available but participant numbers are generally limited. On the other hand, pulsed radiofrequency and electrostimulation as well as Botox have an additional element of safety since they do not involve the risk of phenol and alcohol injections or tissue destruction. The applications of these techniques are operator dependent, which will influence response rates and ultimately benefits.

\section{Abbreviations}

$5 \mathrm{HT}_{3}$, 5-hydroxytryptamine (serotonin); Botox, botulinum toxin A; DNIC, diffuse noxious inhibitory control; NRS, numerical rating scale; THC, tetrahydrocannabinol; $\mathrm{TRPV}_{1}$, transient receptor potential cation channel, subfamily V, member 1; VAS, visual analogue scale.

\section{Competing interests}

The author declares that he has no competing interests.

\section{Acknowledgments}

The author would like to recognize and thank Kerri Jones, Crystal Cernanec and Michele Wells for preparing this manuscript.

\section{References}

I. Brennan F, Carr DB, Cousins M: Pain management: a fundamental human right. Anesth Analg 2007, 105:205-2I.

FI000 Factor 6.0 Must Read

Evaluated by Lynda Wells 13 Aug 2007

2. Breivik H, Cherny N, Collett B, de Conno F, Filbet M, Foubert AJ, Cohen R, Dow L: Cancer-related pain: a pan-European survey of prevalence, treatment, and patient attitudes. Ann Oncol 2009, 20:1420-33.

FI000 Factor 4.8 Must Read

Evaluated by Michael Fisch 08 Oct 2009, Mellar Davis 27 Oct 2009

3. Apolone G, Corli O, Caraceni A, Negri E, Deandra S, Monanari M, Greco MT: Pattern and quality of care of cancer pain 
management. Results from the cancer pain outcome research study group. $\mathrm{Br}$ J Cancer 2009, I00:I566-74.

FI000 Factor 6.0 Must Read

Evaluated by Victor Chang 06 Nov 2009

4. Mantyh PW: Cancer pain and its impact on diagnosis, survival and quality of life. Nat Rev Neurosci 2006, 7:797.

FI000 Factor 3.2 Recommended

Evaluated by Andrew Wilcock 07 Mar 2007, Mellar Davis 14 Dec 2007

5. Christo PJ, Mazloomdoost D: Cancer pain and analgesia. Ann NY Acad Sci 2008, I I 38:278-98.

6. Hanks GW, de Conno F, Cherny N, Hanna M, Kalso E, McQuay HJ, Mercadante S, Meynadier J, Poulain P, Ripamonti C, Radbruch L, Roca I Casas J, Sawe J, Twycross RG, Ventafridda V: Morphine and alternative opioids in cancer pain: the EAPC recommendations. Br J Cancer 200I, 84:587-93.

7. Pappagallo $M$, Oaklander AL, Quatrano-Piacentini AL, Clark MR, Raja SN: Heterogenous patterns of sensory dysfunction in postherpetic neuralgia suggest multiple pathophysiologic mechanisms. Anesthesiology 2000, 92:69I-8.

8. Attal N, Fermanian C, Fermanian J, Lanteri-Minet M, Alchaar $\mathrm{H}$, Bouhassira D: Neuropathic pain: are there distinct subtypes depending on the aetiology or anatomical lesion? Pain 2008, 138:343-53.

FI000 Factor 3.0 Recommended

Evaluated by Nanna Finnerup 05 May 2009

9. Drewes AM, Gregersen H, Arendt-Nielsen L: Experimental pain in gastroenterology: a reappraisal of human studies. Scand J Gastroenterol 2003, 38: I I5-30.

10. Arent-Nielsen L, Curatolo M, Drewes A: Human experimental pain models in drug development: translational pain research. Curr Opin Investig Drugs 2007, 8:4I-53.

II. Staahl C, Estrup Olesen A, Andresen T, Arendt-Nielsen L, Mohr Drewes A: Assessing efficacy of non-opioid analgesics in experimental pain models in health volunteers - an updated review. Br J Clin Pharmacol 2009, 68:322-4I.

12. Johnson JR, Burnell-Nugent M, Lossignol D, Ganae-Motan, Potts R, Fallon MT: Multicenter, double-blind, randomized, placebocontrolled, parallel-group study of the efficacy, safety and tolerability of THC: CBD extract and THC extract in patients with intractable cancer-related pain. J Symptom Pain Manage 2010, 39:167-79.

13. Gatti A, Sabato AF, Occhioni R, Baldeschi GC, Reale C: Controlledrelease oxycodone and pregabalin in the treatment of neuropathic pain: results of a multicenter Italian study. Eur Neurol 2009, 6 I: I29-37.

14. Gilron I, Bailey JM, Dongsheng T, Holden RR, Weaver DF, Houlden RL: Morphine, gabapentin, or their combination for neuropathic pain. $N$ Engl J Med March 2005, 352:1324-34.

\section{Changes Clinical Practice}

FI000 Factor 6.5 Must Read

Evaluated by Howard Gutstein 16 Nov 2005, Michael Serpell 12 Dec 2005, Nadine Attal 13 Feb 2006

15. Gilron I, Bailey JM: Nortriptyline and gabapentin, alone and in combination for neuropathic pain: a double-blind, randomized controlled crossover trial. Lancet 2009, 374:|252-6I.

FI000 Factor 4.9 Must Read

Evaluated by Nanna Finnerup 02 Dec 2009, Joel Katz II Dec 2009, Didier Bouhassira 2I Dec 2009

16. Shibasaki M, Kurokawa K, Ohkuma S: Role of alpha2/delta subunit in the development of morphine-induced rewarding effect and behavioral sensitization. Neuroscience 2009, I 63:73|-4.

17. D'Mello R, Dickenson AH: Spinal cord mechanisms of pain. $\mathrm{Br} J$ Anaesth 2008, I01:8-16.
18. Suzuki R, Rygh LJ, Dickenson AH: Bad news from the brain: descending 5 -HT pathways that control spinal pain processing. Trends Pharmacol Sci 2004, 25:6I3-7.

19. Verdu B, Decosterd I, Buclin T, Stiefel F, Alexandre B: Antidepressants for the treatment of chronic pain. Drugs 2008, 68:26II-32.

Changes Clinical Practice

FI000 Factor 3.0 Recommended

Evaluated by Malcolm Lader 26 Jan 2009

20. Bannister K, Bee LA, Dickenson AH: Preclinical and early clinical investigations related to monoaminergic pain modulation. Neurotherapeutics 2009, 6:703-12.

21. Kardash KJ, Sarrazin F, Tessler MJ, Velly AM: Single dose dexamethasone reduces dynamic pain after total hip arthroplasty. Anesth Analg 2008, I06:I253-7.

FI000 Factor 3.2 Recommended

Evaluated by Brendan Finucane 12 Jun 2009, Mellar Davis 14 Jul 2009

22. Taguchi H, Oishi K, Sakamoto S, Shingu K: Intrathecal betamethasone for cancer pain in the lower half of the body: a study of its analgesic efficacy and safety. Br J Anaesth 2007, 3:385-9.

FI000 Factor 3.0 Recommended Evaluated by Michael Serpell II Jun 2007

23. Thangaswamy CR, Rewari V, Trikha A, Dehran M, Chandralekha: Dexamethasone before total laparoscopic hysterectomy: a randomized controlled dose response study. J Anesth January 2010, 24:24-30.

24. Jokela RM, Ahonen JV, Tallgren MK, Marjakangas PC, Korttila KT: The effective analgesic dose of dexamethasone after laparoscopic hysterectomy. Anesth Analg 2009, 109:607-I5.

25. Mathiesen $\mathrm{O}$, Rasmussen ML, Dierking G, Lech $\mathrm{K}$, Hilsted KL, Fomsgaard JS, Lose G, Dahl JB: Pregabalin and dexamethasone in combination with paracetamol for postoperative pain control after abdominal hysterectomy. A randomized clinical trial. Acta Anaesthesiol Scand 2009, 53:227-35.

26. Wen ZH, Wu GH, Chang YC, Wang J, Wong CS: Dexamethasone modulates the development of morphine tolerance and expression of glutamate transporters in rats. Neuroscience 2005, 133:807-17.

27. Wen ZH, Chang YC, Cherng CH, Wang J], Tao PL, Wong CS: Increasing of intrathecal CSF excitatory amino acids concentration following morphine challenge in morphine-tolerant rats. Brain Res 2004, 995:253-9.

28. Zschocke J, Bayatti N, Clement AM, Witan H, Figiel M, Engele J, Behl C: Differential promotion of glutamate transporter expression and function by glucocorticoid in astrocytes from various brain regions. J Biol Chem 2005, 280:34924-32.

29. Ture H, Sayin M, Karlikaya G, Bingol CA, Aykac B, Ture U: The analgesic effect of gabapentin as prophylactic anticonvulsant drug on postcraniotomy pain: a prospective randomized study. Anesth Analg 2009, I09:|625-31.

FI000 Factor 3.0 Recommended

Evaluated by Nicolas Bruder 27 Oct 2009

30. Kong VKF, Irwin MG: Gabapentin: a multimodal perioperative drug?. Br J Anaesth 2007, 6:775-86.

FI000 Factor 6.4 Must Read

Evaluated by Michael Serpell 18 Jan 2008, Mellar Davis 27 May 2008

3I. Tiippana EM, Hamunen K, Kontinen VK, Kalso E: Do surgical patients benefit from perioperative gabapentin/pregabalin? A systematic review of efficacy and safety. Anesth Analg June 2007, I04: 1545-56.

Changes Clinical Practice

FI000 Factor 6.0 Must Read

Evaluated by Michael Schaefer 20 Feb 2009 
32. Eroglu C, Allen NJ, Susman MW, O'Rourke NA, Park CY, Ozkan E, Chakraborty C, Mulinyawe SB, Annis DS, Huberman AD, Green EM, Lawler J, Dolmetsch R, Garcia KC, Smith S, Luo ZD, Rosenthal A, Mosher DF, Barres BA: Gabapentin receptor a28-I is a neuronal thrombospondin receptor responsible for excitatory CNS synaptogenesis. Cell 2009, 380:380-92.

FI000 Factor 9.7 Exceptional

Evaluated by Shai Shaham 27 Oct 2009, Gerald Zamponi 29 Oct 2009, Keith James 24 Nov 2009

33. Berry J, Lottrum KL: A single dose of gabapentin reduces acute pain and allodynia in patients with herpes zoster. Neurology 2005, 65:444-7.

FI000 Factor 4.8 Must Read

Evaluated by Michael Serpell 16 Jan 2006, Kieron Leslie 20 Oct 2006

34. Mercadante S, Arcuri E, Ferrera P, Villari P, Mangione S: Alternative treatments of breakthrough pain in patients receiving spinal analgesics for cancer pain. J Pain Symptom Manage 2005, 30:5.

Changes Clinical Practice

FI000 Factor 3.0 Recommended

Evaluated by Michael Fisch 06 Dec 2005

35. Norrbrink C: Transcutaneous electrical nerve stimulation for treatment of spinal cord injury neuropathic pain. J Rehab Res Dev 2009, 46:85-93.

36. Van Calenbergh F, Gybels J, Van Laere K, Dupont P, Plaghki L, Depreitere B, Kupers R: Long term clinical outcome of peripheral nerve stimulation in patients with chronic peripheral neuropathic pain. Surg Neurol 2009, 72:330-5.

37. Vallejo R, Kramer J, Benyamin R: Neuromodulation of the cervical spinal cord in the treatment of chronic intractable neck and upper extremity pain: a case series and review of the literature. Pain Physician 2007, 10:305-II.

38. Velasco F, Carrillo-Ruiz JD, Castro G, Argüelles C, Velasco AL, Kassian A, Guevara U: Motor cortex electrical stimulation applied to patients with complex regional pain syndrome. Pain 2009, 174:91-8.

39. Lefaucheur JP, Drouot $X$, Cunin $P$, Bruckert $R$, Lepetit $H$, Créange $A$, Wolkenstein P, Maison P, Keravel Y, Nguyen JP: Motor cortex stimulation for the treatment of refractory peripheral neuropathic pain. Brain 2009, I32: I463-7I.

FI000 Factor 6.0 Must Read

Evaluated by Didier Bouhassira 12 Oct 2009

40. Antal A, Terney D, Kuhnl S, Paulus W: Anodal transcranial direct current stimulation of the motor cortex ameliorates chronic pain and reduces short intracortical inhibition. J Pain Symptom Manage 2010, 39:890-903.

41. Strafella AP, Vanderwerf $Y$, Sadikot AF: Transcranial magnetic stimulation of the human motor cortex influences the neuronal activity of subthalamic nucleus. Eur J Neurosci 2004, 20:2245-9.

42. Gaynor LM, Kühn AA, Dileone M, Litvak V, Eusebio A, Pogosyan A, Androulidakis AG, Tisch S, Limousin P, Insola A, Mazzone P, Di Lazzaro V, Brown P: Suppression of beta oscillations in the subthalamic nucleus following cortical stimulation in humans. Eur J Neurosci 2008, 28:1686-95.

43. Filali M, Hutchison WD, Palter VN, Lozano AM, Dostrovsky JO: Stimulation-induced inhibition of neuronal firing in human subthalamic nucleus. Exp Brain Res 2004, 156:274-81.

44. Desbois $C$, Villanueva $L$ : The organization of lateral ventromedial thalamic connections in the rat: a link for the distribution of nociceptive signals to widespread cortical regions. Neuroscience 200I, 102:885-98.

45. Rico AJ, Barroso-Chinea P, Conte-Perales L, Roda E, GómezBautista V, Gendive M, Obeso JA, Lanciego JL: A direct projection from the subthalamic nucleus to the ventral thalamus in monkeys. Neurobiol Dis 2010, 39:38I-92.
46. Cahana A, Vutskits L, Muller D: Acute differential modulation of synaptic transmission and cell survival during exposure to pulsed and continuous radiofrequency energy. J Pain 2003, 4: $197-202$.

47. Hamann W, Abou-Sherif S, Thompson S, Hall S: Pulsed radiofrequency applied to dorsal root ganglia causes a selective increase in ATF3 in small neurons. Eur J Pain 2006, 10:17|-6.

48. Erdine S, Bilir A, Cosman ER, Cosman ER Jr: Ultrastructural changes in axons following exposure to pulsed radiofrequency fields. Pain Pract 2009, 9:407-17.

49. Brennan L, Fitzgerald J, McCrory C: The use of pulsed radiofrequency treatment for chronic benign pancreatitis pain. Pain Pract 2009, 9:135-40.

50. Vanelderen P, Rouwette T, De Vooght P, Puylaert M, Heylen R, Vissers K, Van Zundert J: Pulsed radiofrequency for the treatment of occipital neuralgia: a prospective study with 6 months of follow-up. Reg Anesth Pain Med 2010, 35:I48-5I.

FI000 Factor 3.0 Recommended

Evaluated by Jason Brooks 09 Apr 2010

51. Cohen SP, Strassels SA, Kurihara C, Crooks MT, Erdek MA, Forsythe A, Marcuson M: Outcome predictors for sacroiliac joint (lateral branch) radiofrequency denervation. Reg Anesth Pain Med 2009, 34:206-14.

52. Cohen SP, Sireci A, Wu CL, Larkin TM, Williams KA, Hurley RW: Pulsed radiofrequency of the dorsal root ganglia is superior to pharmacotherapy or pulsed radiofrequency of the intercostal nerves in the treatment of chronic postsurgical thoracic pain. Pain Physician 2006, 9:227-35.

53. Uchida K: Radiofrequency treatment of the thoracic paravertebral nerve combined with glucocorticoid for refractory neuropathic pain following breast cancer surgery. Pain Physician 2009, I2:E277-83.

54. Bogduk N, Dreyfuss $P$, Govind J: A narrative review of lumbar medial branch neurotomy for the treatment of back pain. Pain Med 2009, I0:1035-45.

55. Abejón D, Ortego R, Solís R, Alaoui N, del Saz J, del Pozo C: Transfacet joint approach to pulsed radiofrequency ablation of the L5 dorsal root ganglion in a patient with degenerative spondylosis and scoliosis. Pain Pract 2008, 8:202-5.

56. van Wijk RM, Geurts JW, Wynne HJ, Hammink E, Buskens E, Lousberg R, Knape JT, Groen G]: Radiofrequency denervation of lumbar facet joints in the treatment of chronic low back pain. Clin J Pain 2005, $21: 335-44$.

57. Nath S, Nath CA, Pettersson K: Percutaneous lumbar zygapophysial (facet) joint neurotomy using radiofrequency current, in the management of chronic low back pain. Spine 2008, 33:1291-97.

58. Datta S, Lee M, Falco FJ, Bryce DA, Hayek SM: Systematic assessment of diagnostic accuracy and therapeutic utility of lumbar facet joint interventions. Pain Physician 2009, 12:437-60.

59. Stone JA, Bartynski WS: Treatment of facet and sacroiliac joint arthropathy: steroid injections and radiofrequency ablation. Tech Vasc Interv Radiol 2009, I 2:22-32.

60. van Wijk RM, Geurts JW, Lousberg R, Wynne HJ, Hammink E, Knape JT, Groen GJ: Psychological predictors of substantial pain reduction after minimally invasive radiofrequency and injection treatments for chronic low back pain. Pain Med 2008, 9:2|2-2I

6I. Rupert MP, Lee M, Manchikanti L, Datta S, Cohen SP: Evaluation of sacroiliac joint interventions: a systematic appraisal of the literature. Pain Physician 2009, 12:399-4I8.

62. Kapural L: Sacroiliac joint radiofrequency denervation: who benefits? Reg Anesth Pain Med 2009, 34:185-6.

63. Garcea G, Thomasset S, Berry DP, Tordoff S: Percutaneous splanchnic nerve radiofrequency ablation for chronic abdominal pain. ANZ J Surg 2005, 75:640-4. 
64. Fonoff ET, de Oliveira YS, Lopez WO, Alho EJ, Lara NA, Teixeira MJ: Endoscopic-guided percutaneous radiofrequency cardotomy. J Neurosurg 2010, [Epub ahead of print].

65. Munk PL, Rashid F, Heran MK, Papirny M, Liu DM, Malfair D, Badii M, Clarkson PW: Combined cemetoplasty and radiofrequency ablation in the treatment of painful neoplastic lesions of bone. J Vasc Inter Radiol 2009, 20:903-II.

66. Apfel SC: Botulinum toxin for neuropathic pain? Neurology 2009, 72:1456-57.

67. Smith HS: Botulinum toxins for analgesia. Pain Physician 2009, I 2:479-8I.

68. Ngeow WC, Nair R: Injection of botulinum toxin type $\mathbf{A}$ (BOTOX) into trigger zone of trigeminal neuralgia as a means to control pain. Oral Surg Oral Med Oral Pathol Oral Radiol Endod 2010, 109:47-50

69. Huang YC, Wei SH, Wang HK, Lieu FK: Ultrasonographic guided botulinum toxin type $A$ treatment for plantar fasciitis: an outcome-based investigation for treating pain and gait changes. J Rehab Med 2010, 42:136-40.

70. Venancio Rde A, Alencar FG Jr, Zamperini C: Botutinum toxin, lidocaine, and dry-needling injections in patients with myofascial pain and headaches. Cranio 2009, 27:46-53.

7I. Gupta M, Patel T, Xavier K, Maruffo F, Lehman D, Walsh R, Landman J: Prospective randomized evaluation of periureteral botulinum toxin type $A$ injection for ureteral stent pain reduction. J Urol 2010, 183:598-602.

72. Festen S, Gisbertz SS, van Schaagen F, Gerhards MF: Blinded randomized clinical trial of botulinum toxin versus isosorbide dinitrate ointment for treatment of anal fissure. Br J Surg 2009, 96:1393-9.
73. Ranoux D, Attul N, Morain F, Bouhassira D: Botulinum toxin type $A$ induces directs analgesic effects in chronic neuropathic pain. Ann Neurol 2008, 64:274-84.

FI000 Factor 4.8 Must Read

Evaluated by Troels Jensen 06 Jan 2009, Claudia Sommer 09 Jan 2009

74. Tracey I, Mantyh PW: The cerebral signature for pain perception and its modulation. Neuron 2007, 55:377-9I.

75. Parris WC, Janicki PC, Johnson B, Horn JL: Intrathecal ketorolac tromethamine produces analgesia after chronic constriction injury of sciatic nerve in rat. Can J Anaesth 1996, 43:867-70.

76. Lashbrook JM, Ossipov MH, Hunter JC, Raffa RB, Tallarida RJ, Porreca F: Synergistic antiallodynic effects of spinal morphine with ketorolac and selective COXI- and COX2- inhibitors in nerve-injured rats. Pain 1999, 82:65-72.

77. Ma W, Du W, Eisenach JC: Role for both spinal cord COX-I and COX-2 in maintenance of mechanical hypersensitivity following peripheral nerve injury. Brain Res 2002, 937:94-9.

78. Suyama H, Kawamoto M, Gaus S, Yuge O: Effect of etodolac, a COX-2 inhibitor, on neuropathic pain in a rat model. Brain Res 2004, I01 0:144-50.

79. Inoue $\mathrm{N}$, Ito $\mathrm{S}$, Tajima $\mathrm{K}$, Nogawa $\mathrm{M}$, Takahashi $\mathrm{Y}$, Sasagawa $\mathrm{T}$, Nakamuru A, Kyoi T: Etodolac attenuates mechanical allodynia in a mouse model of neuropathic pain. J Pharmacol Sci 2009, 109:600-5.

80. Ripamonti C, Ticozzo C, Zecca E, Rodriguez CH, De Conno F: Continuous subcutaneous infusion of ketorolac in cancer neuropathic pain unresponsive to opioid and adjuvant drugs. A case report. Tumori 1996, 82:413-5.

8I. Kausar F, Davis MP: Ketorolac in neuropathic pain. J Pain Symptom Manage 2006, 32:202-4. 